\title{
Capillary blood collection in haematology
}

\author{
J. STUART, B. A. BARRETT, AND D. R. PRANGNELL \\ From the Department of Haematology, The Children's Hospital, Birmingham
}

SYNOPSIS A capillary blood collection technique which facilitates the estimation of routine haematological parameters, including platelet count and sedimentation rate, is described. The technique requires $0.5 \mathrm{ml}$ of blood, allows closer reproducibility than pipette collection methods, is suitable for monitoring blood counts in patients receiving cytotoxic agents, and can be integrated with semiand fully-automated production lines.

The ability to collect capillary blood from thumb or heel is essential in paediatric haematology. Capillary blood specimens for routine blood tests are usually collected into several individual pipettes and the appropriate dilutions made at the bedside (Brecher, Schneiderman, and Cronkite, 1953; Lewis and Benjamin, 1965; Dacie and Lewis, 1968; Brecher, 1971). This is time consuming and can be technically difficult, particularly when the child is in an incubator. When the specimens reach the laboratory they may require to be processed separately from the semi- and fully-automated production lines used for venous blood. A major disadvantage of pipette collection and dilution at the bedside is that additional tests cannot be performed, or an abnormal test result repeated, without a return visit to the patient.

A simplified collection technique in which $0.5 \mathrm{ml}$ of capillary blood is taken directly into a single plastic container is described. A micro-method for estimation of the erythrocyte sedimentation rate (ESR) on the same blood sample has been developed simultaneously.

\section{Methods}

TUBE COLLECTION TECHNIQUE

Two different collecting tubes for capillary blood were studied: a glass precipitin tube $(50 \times 6 \mathrm{~mm})$ and a $1.0 \mathrm{ml}$ capacity plastic haematology tube for paediatric use $(27 \times 12 \mathrm{~mm})^{1}$. The latter was obtained without anticoagulant and a line was drawn to indicate the $0.5 \mathrm{ml}$ level. A $50 \mu \mathrm{l}$ volume

${ }^{1}$ Teklab (Medical Laboratories) Ltd, Dorothy Crescent, Sacriston, Co. Durham.

Received for publication 5 August 1974. of $1.8 \% \mathrm{w} / \mathrm{v}$ dipotassium ethylenediamine tetraacetic acid (EDTA) was added to each tube and dried at $37^{\circ} \mathrm{C}$ for at least 24 hours for plastic tubes and at $160^{\circ} \mathrm{C}$ overnight for glass tubes. The precipitin tubes were sealed by a rubber bung.

Capillary blood was obtained from the pulp of the thumb or from the heel after cleansing with $70 \%$ isopropyl alcohol BP and wiping dry before puncturing to a depth of $2-3 \mathrm{~mm}$ using a disposable lancet. Free-flowing blood was obtained using gentle pressure only and after the first drop of blood had been discarded, subsequent drops were collected by a rapid scooping motion against the skin (fig 1). Blood was mixed with the dried anticoagulant by intermittent flicking of the bottom of the tube with the ring finger during collection. A total of $0.5 \mathrm{ml}$ of blood was collected in each case.

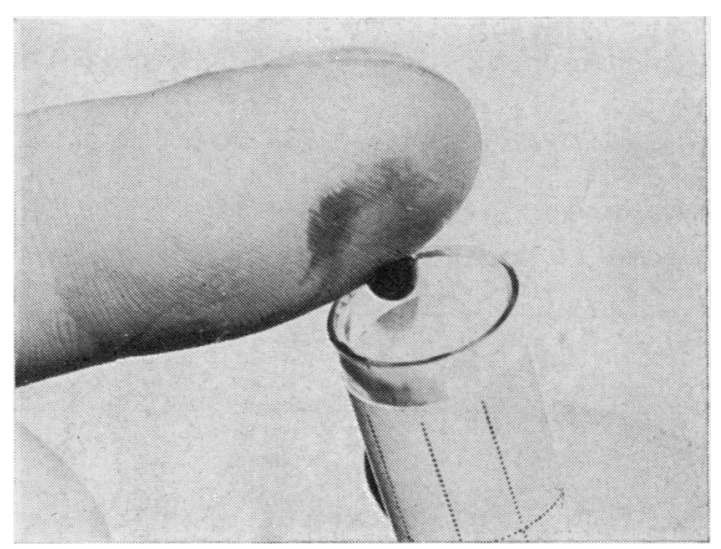

Fig 1 Capillary blood collection technique using $0.5 \mathrm{~m}$ capacity plastic tube. 
PIPETTE COLLECTION TECHNIQUE

Capillary blood was collected into disposable $20 \mu \mathrm{l}$ capacity glass capillary tubes ${ }^{2}$ for haemoglobin estimation (Hb) and into microhaematocrit tubes ${ }^{3}$ for packed cell volume (PCV). Blood for platelet enumeration was collected into Thoma white cell pipettes (Hardisty and Ingram, 1965).

\section{MICRO-METHOD FOR ESR}

An Accu-Tech ESR system ${ }^{4}$ incorporating a suction motor and self-levelling device was used. MicroESR disposable plastic tubes $(1 \mathrm{~mm}$ bore and $200 \mathrm{~mm}$ length to level of plug) were specially prepared by the manufacturer. The tubes were filled with blood (diluted 4 parts blood to 1 part $31.3 \mathrm{~g} / 1$ trisodium citrate) and maintained vertically at room temperature for $60 \mathrm{~min}$ before reading. The method required only $0.3 \mathrm{ml}$ of undiluted blood.

\section{HAEMATOLOGICAL METHODS}

Haematological values were determined by standard methods (Dacie and Lewis, 1968) using either a semi-automated production line with autodiluters or a Coulter model S. Capillary blood specimens estimated by the latter instrument were first diluted 1 in 224 using an autodiluter.

Platelets were counted by phase contrast microscopy using coded specimens to prevent technician bias.

Statistical significance was determined by the Wilcoxon signed-rank test for matched pairs and by the $\mathrm{F}$ distribution for difference between variances.

\section{Results}

COMPARISON BETWEEN PLASTIC AND GLASS TUBES

A comparison was made between the two types of

2Drummond Microcaps (gold line), Shandon Southern Ltd, Camberley, Surrey.

'Gelman Hawksley, 12 Peter Road, Lancing, Sussex.

4Accu-Tech, P.O. Box 6, Littleborough, Lancs. tube used for the direct collection of capillary blood. Care was required when using the glass precipitin tube to ensure that each drop of blood ran down the trail left by the preceding drop on the side-wall in order to ensure minimal platelet activation and clumping. Despite this precaution the individual platelet counts for 10 children using glass tubes (mean value $191 \times 10^{9} / 1$ ) were significantly lower $(P<0.05)$ than the equivalent individual counts for plastic tubes (mean value $207 \times 10^{9} / 1$ ), although the mean values were not significantly different.

The size and shape of the plastic tube was also found to be superior to the glass precipitin tube: it was easier to handle during blood collection; the flat base facilitated transport and handling in the laboratory; the tube could be accommodated by a variety of laboratory mixing devices; and the wider orifice facilitated removal of samples by an autodiluter.

COMPARISON BETWEEN $0.5 \mathrm{ML}$ AND $2 \cdot 5 \mathrm{ML}$ CAPACITY TUBES

Venous blood from 10 adult patients was distributed simultaneously into the $0.5 \mathrm{ml}$ plastic tube and into conventional $2.5 \mathrm{ml}$ capacity glass tubes containing EDTA $^{5}$. There was no significant difference $(P>0 \cdot 1)$ in the results for the two types of tube in respect of $\mathrm{Hb}, \mathrm{PCV}$, red cell count (RCC), mean cell volume (MCV), white cell count (WCC), or platelet count (table I).

\section{COMPARISON BETWEEN TUBE AND PIPETTE COLLECTION}

Capillary blood was collected from 10 children using the $0.5 \mathrm{ml}$ plastic tube for one thumb and individual pipettes for the other. There was no significant difference $(P>0.1)$ between the two collection techniques for $\mathrm{Hb}$ or $\mathrm{PCV}$, but the individual platelet counts obtained by the pipette 'sandwich' technique were significantly lower $(P<0.05)$ than the platelet counts obtained from the plastic tubes (table II).

'Labco Ltd, Meadow Bottom Road, Marlow, Bucks.

\begin{tabular}{lccc}
\hline \multirow{2}{*}{ Test } & Mean Values & \multicolumn{1}{c}{$\begin{array}{l}\text { Significance of Difference } \\
\text { Between Paired Data } \\
\text { (Wilcoxon) }\end{array}$} \\
\cline { 2 - 4 } & $0.5 \mathrm{ml}$ Tube & $2.5 \mathrm{ml}$ Tube & $>0.1$ \\
\hline Hb (g/d) & 14.26 & 14.32 & $>0.1$ \\
PCV & 0.415 & 0.416 & $>0.1$ \\
RCC $\left(\times 10^{12} / 1\right)$ & 4.91 & 4.90 & $>0.1$ \\
MCV (f 1$)$ & 85.9 & 86.0 & $>0.1$ \\
WCC $\left(\times 10^{\circ} / 1\right)$ & 6.01 & 5.99 & $>0.1$ \\
Platelets $\left(\times 10^{\circ} / 1\right)$ & 201.1 & 215.0 &
\end{tabular}

Table I Comparison between $0.5 \mathrm{ml}$ capacity plastic tube and $2.5 \mathrm{ml}$ capacity glass tube for 10 venous blood samples 1 ${ }^{1}$ As determined by Coulter model $S$, with exception of platelet count. 


\begin{tabular}{lccc}
\hline Test & Mean Values & \multicolumn{1}{c}{$\begin{array}{l}\text { Significance of Difference } \\
\text { Between Paired Data } \\
\text { (Wilcoxon) }\end{array}$} \\
\cline { 2 - 4 } & Plastic Tube & Pipettes & $>0.1$ \\
$\mathrm{Hb}(\mathrm{g} / \mathrm{dl})$ & 13.90 & 13.88 & $>0.1$ \\
$\mathrm{PCV}$ & 0.415 & 0.424 & $<0.05$ \\
Platelets $(\times 10 \% 1)$ & 210.0 & 162.0 & $>0.02$ \\
\hline
\end{tabular}

Table II Comparison between plastic tube and pipette collection techniques for 10 patients ${ }^{1}$

${ }^{1}$ As determined by semi-automated and manual methods.

\section{ASSESSMENT OF REPRODUCIBILITY}

Duplicate blood specimens were obtained by thumb prick using both thumbs of 30 children. Duplicate specimens were thus collected from 10 children for each of the three methods of collection: plastic tube, glass tube, and pipette methods. The variance of the difference of the results obtained from the paired thumbs was used as a measure of reproducibility. The results (table III) show a significantly closer reproducibility for the plastic tube method, compared with the next best method, for $\mathrm{Hb}$ and platelet count; there was no significant improvement for PCV or WCC.

\section{COMPARISON BETWEEN CAPILLARY AND}

\section{VENOUS BLOOD}

Capillary blood was collected into $0.5 \mathrm{ml}$ plastic tubes from the thumbs of nine adults and venous blood, taken simultaneously, was placed into identical tubes. There was no significant difference between individual capillary and venous blood values for PCV, RCC, MCV, WCC, and platelet count; $\mathrm{Hb}$ values were slightly but significantly higher for capillary blood (table IV).

\section{EFFECT OF STORAGE FOR 24 HOURS}

Capillary blood specimens from 10 patients were studied immediately for $\mathrm{Hb}$, WCC and platelets (day 1) and again after storage for 24 hours at $20^{\circ} \mathrm{C}$ (day 2). There was no significant difference $(\mathrm{P}>0 \cdot 1)$ between the paired values (table V).

\begin{tabular}{|c|c|c|c|}
\hline \multirow[t]{2}{*}{ Test } & \multicolumn{2}{|c|}{ Mean Values } & \multirow{2}{*}{$\begin{array}{l}\text { Significance of } \\
\text { Difference } \\
\text { Between Paired } \\
\text { Data (Wilcoxon) }\end{array}$} \\
\hline & Day 1 & Day 2 & \\
\hline $\begin{array}{l}\mathrm{Hb}(\mathrm{g} / \mathrm{dl}) \\
\text { WCC }\left(\times 10^{\circ} / 1\right) \\
\text { Platelets }\left(\times 10^{\circ} / 1\right)\end{array}$ & $\begin{array}{r}12 \cdot 8 \\
6 \cdot 2 \\
257 \cdot 4\end{array}$ & $\begin{array}{r}13 \cdot 1 \\
5 \cdot 8 \\
272 \cdot 3\end{array}$ & $\begin{array}{l}>0.1 \\
>0.1 \\
>0.1\end{array}$ \\
\hline
\end{tabular}

Table V Effect of storage at $20^{\circ} \mathrm{C}$ for 24 hours on 10 capillary blood specimens ${ }^{1}$

${ }^{1}$ As determined by semi-automated and manual methods

\begin{tabular}{lllll}
\hline Test & Plastic Tube & Glass Tube & Pipettes & Significance \\
\hline Hb & 0.072 & 0.523 & 0.614 & $<0.005$ \\
PCV & 0.000165 & 0.000369 & 0.000594 & $>0.1$ \\
WCC & 1.439 & 1.746 & 4.317 & $>0.1$ \\
Platelets & 547 & 8922 & 2027 & $<0.05$ \\
\hline
\end{tabular}

Table III Variance of difference between duplicate counts on 10 patients for three blood collection techniques ${ }^{1}$ ${ }^{1}$ As determined by semi-automated and manual methods.

${ }^{2}$ Plastic tube method compared with next best method.

\begin{tabular}{|c|c|c|c|}
\hline \multirow[t]{2}{*}{ Test } & \multicolumn{2}{|l|}{ Mean Values } & \multirow{2}{*}{$\begin{array}{l}\text { Significance of Difference } \\
\text { between Paired Data } \\
\text { (Wilcoxon) }\end{array}$} \\
\hline & Capillary Blood & Venous Blood & \\
\hline $\begin{array}{l}\mathrm{Hb}(\mathrm{g} / \mathrm{dl}) \\
\mathrm{PCV} \\
\operatorname{RCC}\left(\times 10^{12} / 1\right) \\
\mathrm{MCV}(\mathrm{f} 1) \\
\text { WCC }\left(\times 10^{9} / 1\right) \\
\text { Platelets }\left(\times 10^{\%} / 1\right)\end{array}$ & $\begin{array}{c}14 \cdot 8 \\
0 \cdot 423 \\
5 \cdot 04 \\
86 \cdot 0 \\
5 \cdot 15 \\
197 \cdot 9\end{array}$ & $\begin{array}{c}14 \cdot 5 \\
0 \cdot 419 \\
4.98 \\
85 \cdot 9 \\
4 \cdot 98 \\
201 \cdot 1\end{array}$ & $\begin{array}{l}<0.02 \\
>0.1 \\
>0.1 \\
>0.1 \\
>0.1 \\
>0.1\end{array}$ \\
\hline
\end{tabular}

Table IV Comparison between capillary and venous blood results for nine patients using $0.5 \mathrm{ml}$ plastic tubes

${ }^{1}$ As determined by Coulter model S, with exception of platelet count. 
COMPARISON BETWEEN MICRO-METHOD ESR AND WESTERGREN ESR

Venous blood specimens sent to the laboratory for routine analysis from 107 children and adults were studied simultaneously for ESR using the micromethod plastic ESR tubes and Westergren-Katz glass ESR tubes (British Standards Institution, 1968). The correlation between the ESR results obtained, for venous blood, is shown in fig 2 ( $r=0.98)$.

The reproducibility of the micro-method was determined by performing duplicate ESRs on 50 venous blood specimens in the range $1-122 \mathrm{~mm}$ in one hour. The correlation between duplicate estimations is shown in fig $3(r=0.99)$.

The micro-method ESR for capillary blood taken directly into the $0.5 \mathrm{ml}$ capacity tube was compared with Westergren ESR for venous blood taken simultaneously into $2.5 \mathrm{ml}$ capacity tubes from 20 patients. The results (table VI) showed close correlation between the two methods ( $r=0.99)$ but the individual values for the capillary ESR were significantly higher $(P<0.01)$ than the paired values for venous blood.

\section{Discussion}

The collection of capillary blood into a single $0.5 \mathrm{ml}$ capacity plastic tube has several advantages over the use of individual pipettes: collection from the

\begin{tabular}{ccc}
\hline & ESR & \\
\cline { 2 - 3 } & Capillary Blood & Venous Blood \\
Micro-method & Westergren \\
\hline & 10 & 7 \\
11 & 7 \\
2 & 2 \\
12 & 10 \\
7 & 5 \\
& 15 \\
9 & 7 \\
& 20 & 15 \\
8 & 5 \\
& 10 & 7 \\
& 10 & 1 \\
& 2 & 4 \\
& 6 & 3 \\
& 6 & 18 \\
& 20 & 15 \\
16 & 6 \\
9 & 2 \\
& 4 & 20 \\
& 60 & $10 \cdot 5$ \\
\hline
\end{tabular}

Table VI Comparison between micro-method ESR for capillary blood and Westergren ESR for venous blood in 20 patients 1

${ }^{1}$ Values shown represent $\mathrm{mm}$ fall in one hour.

patient is easier, especially when the child is struggling or is lying in an incubator; labelling an $\$$ transport of the specimen are simplified; the plastic tube can be processed together with venous: blood specimens on blood mixers and in semi- of

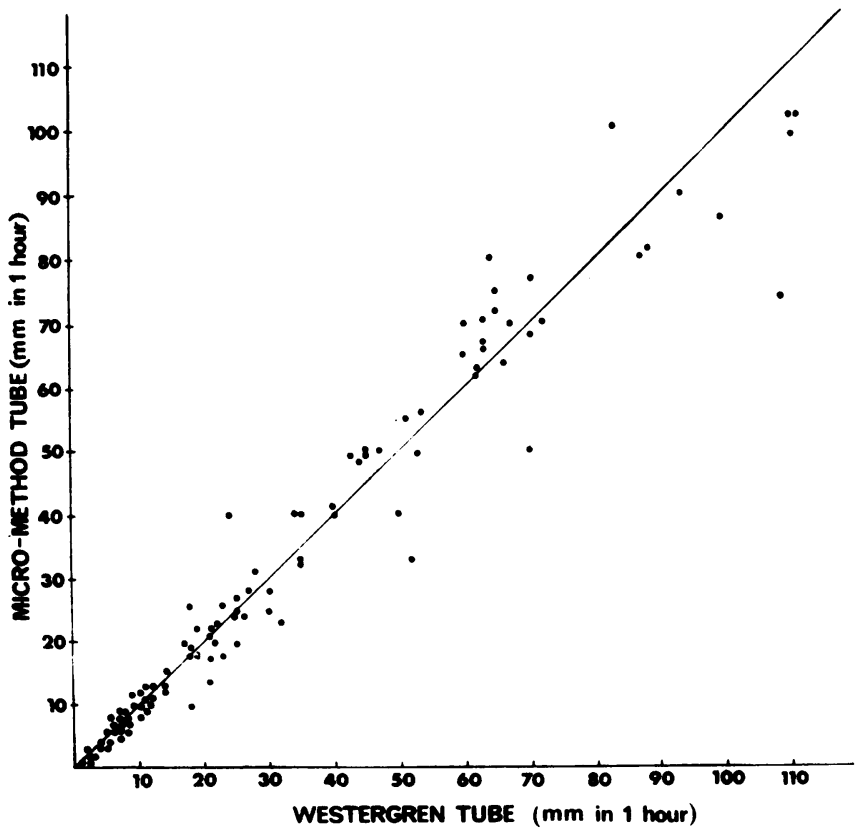

Fig 2 Comparison between micro-method ESR and Westergren ESR on venous blood from 107 patients. The results for 100 comparisons only are illustrated owing to overlap. 


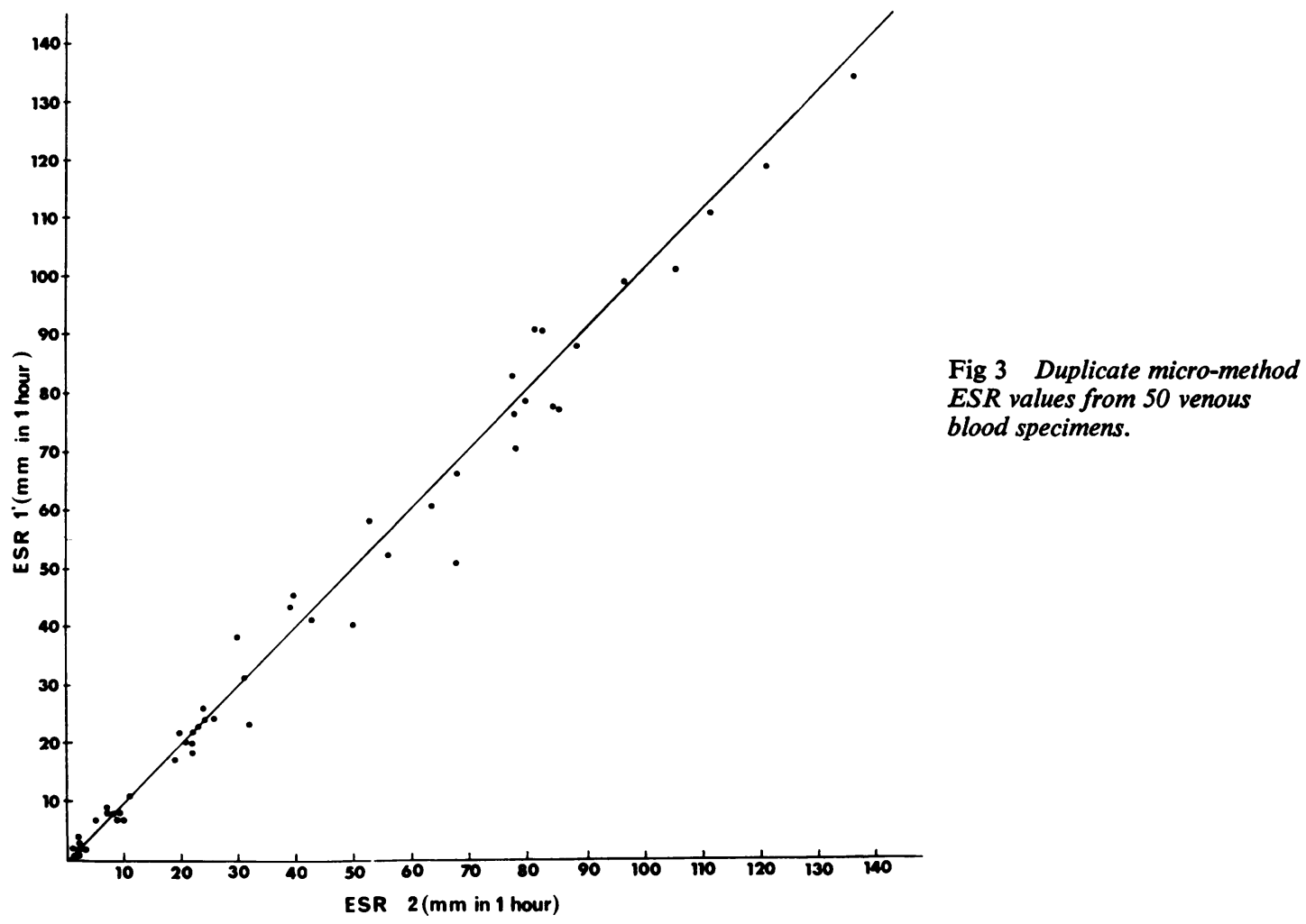

fully-automated production lines; a test can be repeated or additional investigations performed without re-sampling from the patient; and the accuracy and reproducibility of the technique appear to be improved.

There are several technical points which are relevant to all capillary blood collection techniques. The area to be sampled should be warm, firmly immobilized, and all traces of perspiration should be removed. A good flow of blood should be obtained, the first drop discarded, and the subsequent collection performed as rapidly as possible without excessive pressure. Care must be taken to ensure that the blood and anticoagulant are continuously mixed, in our case by flicking the base of the tube, throughout the collection period. With these safeguards, capillary blood samples will give routine haematological values, platelet counts (Brittin, Dew, and Fewell, 1971), and also coagulation factor levels (Stuart, Picken, Breeze, and Wood, 1973), which approximate closely to those of venous blood. The concentration of EDTA in the plastic tubes may, however, result in a falsely low PCV (Lampasso, 1965) if significantly less than $0.5 \mathrm{ml}$ of blood is collected.

The micro-method for ESR determination, which utilizes $0.3 \mathrm{ml}$ of blood, showed good correlation for venous blood with the Westergren ESR reference method (International Committee for Standardization in Hematology, 1973). There was no trend to lower values for the micro-method as reported for earlier micro techniques (Hazelton, 1973). The micro-ESR plastic tubes were provided as an early sample by the manufacturer and improvements in quality control of the bore are anticipated. The sample tubes tested gave satisfactory reproducibility for duplicate ESR estimations but further studies are required on subsequent batches.

The ESR values for venous and capillary blood are said to be comparable (Nicholls, 1942) although our own individual values for 20 capillary ESR readings were significantly higher than the paired Westergren values for venous blood. This also requires further study, particularly at higher ESR levels.

The capillary blood collection technique has been used for all routine blood counts in the department for the past six months and has been of particular value in monitoring patients receiving cytotoxic drugs. The average collection time from thumb prick to closing the tube is one minute and there have 
been no difficulties with micro-clot formation. There was no significant change in $\mathrm{Hb}$, WCC, or platelet count after storage at room temperature for 24 hours and this collection technique may therefore be of value for community health and general practitioner screening studies in paediatrics when a postal service is used.

We are grateful to Teklab (Medical Laboratories) Ltd and Accu-Tech for making available preproduction samples of capillary blood collecting tubes and micro-ESR tubes respectively. Dr A. Pollock kindly provided access to a Coulter model S.

\section{References}

Brecher, G. (1971). Enumeration of blood platelets: methods and their validity. In The Platelet, edited by $\mathrm{K}$. M. Brinkhous, R. W. Shermer, and F. K. Mostofi, pp. 358-364. Williams and Wilkins, Baltimore.

Brecher, G., Schneiderman, M., and Cronkite, E. P. (1953). The reproducibility and constancy of the platelet count. Amer. $J$. clin. Path., 23, 15-26.

British Standards Institution (1968). Westergren tube for measurement of erythrocyte sedimentation rate. British Standard 2554.

Brittin, G. M., Dew, S. A., and Fewell, E. K. (1971). Automated optical counting of blood platelets. Blood, 38, 422-430.

Dacie, J. V., and Lewis, S. M. (1968). Practical Haematology, 4th ed., p. 10. Churchill, London.

Hardisty, R. M., and Ingram, G. I. C. (1965). Bleeding Disorders, p. 269. Blackwell, Oxford.

Hazelton, J. J. (1973). Erythrocyte sedimentation rate. In Clinical Laboratory Techniques, edited by G. D. Wasley, p. 6. Baillière Tindall, London.

International Committee for Standardization in Hematology (1973). कै Reference method for the erythrocyte sedimentation rate (ESR) test on human blood. J. clin. Path., 26, 301-302.

Lampasso, J. A. (1965). Error in hematocrit value produced by excessive ethylenediaminetetraacetate. Amer. J. clin. Path., 44, $\vec{\omega}$ 109-110.

Lewis, S. M., and Benjamin, H. (1965). Break-off capillary tube $\overrightarrow{0}$ method for blood counts. J. clin. Path., 18, 689.

Nicholls, R. E. (1942). A study of the phenomenon of erythrocyte $N$ sedimentation. J. Lab. clin. Med., 22, 1317-1327.

Stuart, J., Picken, A. M., Breeze, G. R., and Wood, B. S. B. (1973). Capillary-blood coagulation profile in the newborn. Lancet 2, 1467-1471. 